\title{
Noema and Noesis. Part I: Functions of Noetic Synthesis
}

\section{Wojciech Krysztofiak ${ }^{1}$}

Received: 7 May 2019 / Accepted: 27 July 2019 / Published online: 1 August 2019

(C) The Author(s) 2019

\begin{abstract}
In the paper, the formal model of the noetic synthesis functions is presented. Together with the functions of noematic synthesis, they are understood as components of functions of intentional reference, which are meant to be, in turn, formalizations of intentional acts of reference performed in the stream of consciousness. This research perspective allows us to extend the category of speech acts to the category of all intentional acts of reference. The functions of noetic synthesis are understood as composed of the function of noetic intention acting on qualia, noetic moods and noetic modes. The model allows us to explain the phenomenon of autism as having its source in disorders of the noetic synthesis functions. The constructed model is not intended as the faithful reconstruction of the Husserlian conception of noesis. Intuitions of the creator of phenomenology are treated as the only source of inspiration.
\end{abstract}

Keywords Noetic synthesis functions · Noetic intentions · Noetic moods · Qualia · Noetic modes $\cdot$ Autism $\cdot$ Subjectivity $\cdot$ Noema

\section{Introduction}

The paper undertakes the task of building the phenomenological model of the functions of noetic synthesis understood as constituents of intentional acts of consciousness. This task is the first part of a more general enterprise of formalizing a noeticnoematic model of a mental act. ${ }^{1}$ Such a model will become the basis for the formal

\footnotetext{
1 The phenomenological concept of intentionality has several rough formalizations. One of the first attempts of this kind is the intentionality model formulated on the basis of category theory in Barušs (1989). Another way of formal representation of intentional acts is proposed in the works (Marbach 1993, 2010). In Krysztofiak (1995) the formalization of the notion of noema is presented. Yoshimi (2016) presents the formalization of Husserl's conception of intentionality on the ground of Gurwitschian interpretation of phenomenology.
}

Wojciech Krysztofiak

wojciech.krysztofiak@gmail.com

1 The Institute of Philosophy, University of Szczecin, U1. Krakowska 71-79, 71-004 Szczecin, Poland 
theory of elementary speech acts understood as the fusions of at least four other language acts. Every speech act is treated as composed of an act of producing an utterance, a locutionary act, an illocutionary act and an act of communication reference. The locution and illocution structure of a speech act may be interpreted as the noeticnoematic structure of an intentional act of consciousness. In the proposed model, the locutionary constituent of a speech act becomes the special act of expressing a noema of an intentional act of consciousness and the illocutionary constituent of a speech act becomes the special act of expressing of a noesis of an intentional act of consciousness. This research perspective allows us to comprehend the category of illocutions as the special type of intentional acts of reference. In this way, it will be possible to describe, for instance, acts of perception (viewing, looking, hearing, touching, etc.), acts of imagining, acts of remembering, acts of dreaming, acts of asserting, acts of counting, acts of admiring, etc. as possessing their noetic forces which are understood as determined by intentions of consciousness, that is, as determined by aims according to which agents refer toward various fragments of any worlds. If some noematic constituents of intentional acts are interpreted as mental spaces in the meaning of Fauconnier's conception (Fauconnier 1994, 2007), then the proposed theory of the model of a mental act will become a generalization of the speech acts theory, the conception of mental spaces and the conception of consciousness in the meaning of the California School of phenomenology (Føllesdal 1969, 1972; Smith and McIntyre 1982; Krysztofiak 1995; Yoshimi 2007). The model of noetic functions presented in the work is not intended as a faithful reconstruction of Husserl's conception. The analyzes carried out by the creator of phenomenology only serve as a source of inspiration.

\section{The Noetic-Noematic Structure of an Elementary Intentional Act of Consciousness}

The terms of "noesis" and "noema" were introduced into the language of philosophy by Edmund Husserl in order to describe two strata of an intentional act of consciousness. However, the creator of phenomenology explicated these terms in a way that allows their various interpretations. Therefore, commentators of Husserl's philosophy discuss the issue of proper understanding of the mentioned concepts. Especially, the notion of a noema evokes a lot of controversy (Drummond 1997, p 494-499; Kosowski 2008; Mohanty 1985).

Mainly, there are three ways of understanding a noema discussed in phenomenological studies over consciousness and its mechanisms of acting. The first one may be called the transcendental interpretation of a noema within the "appearanceobject" schema. The second way of interpreting noemata consists in comprehending them within the part-whole schema. It is called the Gurwitschian interpretation. The third way of interpreting a noema, sometimes called the Fregean or Californian interpretation, treats it as an intensional mediator in intentional acts of reference to various fragments of any world.

All of aforementioned ways of understanding noemata assume a common framework for their formal modeling. Every mental act of consciousness is an act of reference to something outside a given act (called the intentional object of the act) 
through some content and in some way. This common framework of the structure of conscious intentional acts may be comprehended as the ordered triple of the shape: $<$ the way of capturing an intentional object, the content of an act, the intentional object of an act $>$. Various combinations of constituents of the highlighted structure can serve as the basis for constructing different theoretical entities in the model.

According to the proponents of transcendental interpretation, the ordered couple $<$ the way of capturing an intentional object, the content of the act $>$ is the appearance of the intentional object. A noema would be a couple consisting of the appearance of the intentional object and the given intentional object. In this way, noemata could be understood as special types of reference objects given in special cognitive acts, generated by various phenomenological reduction operations. For example, " \%.../the tree-noema is the tree insofar as it is analyzed as a perceptual object, as articulable in categorical activity, as intendible in absence, as rememberable and so on" (Sokolowski 1987, p 527). According to this description, expressions falling under the scheme: $X$ as conceived in such and such a way, as this and that, would just designate noemata. For example, the phrase " $x$ as perceived visually from a distance, as a tall, green, leafy tree" would designate some noema given in a phenomenologically reduced act of visual perception. In turn, according to Gurwitsch's interpretation (1967a, p 42, 1967b), noemata are contents that are parts of intentional objects understood as some integral bundles of properties encoded in the mind. They would be described by expressions falling under the scheme: $X$ as such and such. The phrase "This tree as tall, green and leafy" would designate a noema as being an aspect of the perceived tree. From the transcendental point of view, noemata are structures of the shape: $<<$ the way of capturing an intentional object, the content of an act $>$, the intentional object $>$. From the Gurwitschian point of view, noemata fall under the structure of the shape: <the content of an act, the intentional object>.

The Californian approach to noemata treats them as mediators in cognitive acts understood as Fregean senses (Føllesdal 1969, 1972). They are embedded in some inter-connections both in relation to intentional objects or situations and to the ways of capturing them. This general proposal of understanding noemata enables us to interpret the way of capturing an intentional object as the noesis of an act and the content of an act as its noema. The main difference holding between the Californian interpretation and the transcendental interpretation is that the former maintains that the noesis of an act and the noema of the same act are constituents of the mind, whereas the latter treats noemata as entities outside of the mind. Furthermore, under transcendental interpretation noetic moments of acts become peculiar moments of noemata. $^{2}$

\footnotetext{
${ }^{2}$ Differences between the Californian model of a noema and its transcendental interpretation are revealed in the dispute between semantic internalists and externalists. The first claim that the reference object of a mental act is determined by the content of mental states, while others argue that apart from the mental determinants in the process of determining the subject matter of an intentional act, external factors that are internal to the environment affect the mind and consciousness. According to Zahavi, the Californian interpretation of noemata is treated as internalist, while the transcendental approach to this category sustains semantic externalism (Zahavi 2004). Some representatives of phenomenology criticize Føllesdal's conception $(1969,1972)$ as the result of a misunderstanding of Husserl's texts (Sokolowski 1987; Drummond 1990, pp 135-138; Banchetti 1993; Balza 2009; Alves 2013). The Californian inter-
} 
The advantage of the Californian conception consists in enabling us to formalize mental acts of reference toward objects or situations as applications of functions of noetic synthesis to functions of noematic synthesis.

\section{The Reference Functions}

Let $R E F$ be a set of all reference functions, the arguments of which are neurophysiological states of the organism $(N E U R)$, while the values are various intentional objects (INT). Performing a reference action can be interpreted as a situation in which the reference function underlying a given action in the mind is active. Let "*" be a predicate indicating that some function is active. In addition, if the reference function is not active, then any event consisting in performing a reference activity does not correspond with it. In this situation, it can be assumed that the reference function returns as its value a blank reference object. Let constant "stop" mean such an object of intentional reference. Let us assume the following axioms:

$$
\begin{array}{ll}
\text { (A1) } & (\forall r)\left[r \in R E F \wedge r^{*} \rightarrow(\exists s, p)(s \in N E U R \wedge p \in I N T \wedge r(s)=p)\right] \\
\text { (A2) } & (\forall r)\left[r \in R E F \wedge \sim r^{*} \rightarrow(\forall s)(s \in N E U R \rightarrow r(s)=s t o p)\right]
\end{array}
$$

According to (A1), for each reference function that is active, there is a neurophysiological state of the organism that the given reference function converts into a specific object of reference. The act of intentional reference is thus understood as the activation state of the specified reference function. Analogously, as in the situation of the work of artificial intelligence, having a coded software by an artificial mind (that is, a system of computational algorithms), does not condition yet that he thinks. In order for such a mind to think, its software must be activated. To speak metaphorically, the computer must first be turned on. The axiom (A2) asserts that every non-active reference function returns a blank reference object.

Let NOESIS be the set of all functions of noetic synthesis and finally NOEMA be the set of all functions of noematic synthesis. Let us define the functions of the set $R E F$ in the following way:

$$
(\mathrm{DF} 1) \quad(\forall r)\left[r \in R E F \equiv_{d f}(\exists h, g)(h \in N O E S I S \wedge g \in N O E M A \wedge r=h(g) \wedge r \neq g]\right.
$$

\footnotetext{
Footnote 2 (continued)

pretation possesses its modifications. According to Mohanty (1985), noemata are mediators in cognitive acts, but they are not Platonic entities. Fregean senses are, however, Platonic entities. If the senses are not interpreted as Platonic beings, then they can be interpreted as a special type of intensional entities. Føllesdal's interpretation, inspired by Hintikka, was expanded in Smith and McIntyre (1982) to the phenomenological conception of possible worlds as constitutive elements of intentionality. According to the so-called Hintikka's thesis, every intentional act of referring to an object always takes place in the context of possible worlds. The more these possible worlds are involved in the act of reference to the object, the more the act is intentional. Intentionality is gradual (Hintikka 1975, 1980).
} 
Every function of intentional reference is the superposition of some function of the noetic synthesis with some function of the noematic synthesis. If arguments of functions of intentional reference are neurophysiological states and their values are intentional objects or situations (or states of affairs), then the argument of any function $h(g)$ is also some neurophysiological state of the organism and its value is some intentional object or situation. In this way, all functions of the shape $h(g)$ may be interpreted as mental representations synthesized and encoded in the mind. Under this proposal, noemata understood as representational functions are arguments of noetic functions. The application of the noetic function $h$ to the noematic function $g$ creates a reference function, which in turn, acting on the appropriate neuronal state of the brain, returns its value as some intentional object. According to (DF1), reference functions may be inactive.

Let us introduce the relational predicate "activates" as denoting the relation of activating a certain function by another function. Let us introduce the following axioms which explicate the meaning of "*" (read as "is active"):

(A3) $\quad(\forall h)\left[h \in N O E S I S \rightarrow\left(h^{*} \equiv(\exists g)(g \in N O E M A \wedge\right.\right.$ hactivates $\left.\left.g)\right)\right]$

(A4) $\quad(\forall h)\left[h \in N O E S I S \wedge h^{*} \rightarrow(\exists g)(g \in N O E M A \wedge h\right.$ activates $\left.g \wedge h(g) \epsilon R E F)\right]$

(A5) $(\forall h, g)\left[h \in N O E S I S \wedge g \in N O E M A \rightarrow\left(h^{*} \wedge\right.\right.$ hactivates $\left.\left.g \rightarrow g^{*} \wedge h(g) *\right)\right]$

$(\forall h, g)\left[h \in N O E S I S \wedge g \in N O E M A \rightarrow\left(h^{*} \wedge \sim\right.\right.$ hactivates $\left.\left.g \rightarrow \sim h(g)^{*}\right)\right]$

According to (A3), for every function of noetic synthesis $h, h$ is active if and only if there is a function of noematic synthesis $g$ that $h$ activates $g$. (A4) expresses the phenomenological general principle of noetic-noematic correlation. According to this axiom, for every function of noetic synthesis $h$ that is active, there is a function of noematic synthesis $g$ that $h$ activates $g$ and the superposition $h(g)$ is a reference function. According to (A5), for each function of noetic synthesis $h$ and each function of noematic synthesis $g$, if $h$ is active and $h$ activates $g$, then $g$ is active and the reference function $h(g)$ is also active. (A5) does not exclude a case that $h(g)$ and $g$ are active, whereas $h$ is not active. So, (A5) preserves the possibility of the active unconscious states of the mind. (A6) excludes the situation in which an active function of noetic synthesis does not activate some function of noematic synthesis and their superposition is an active function.

\section{The Stream of Consciousness as Sequences of Applications of Noetic Functions to Noematic Functions}

In phenomenology, consciousness is comprehended as a stream of intentional acts directed toward various intentional objects or situations. Fragments of consciousness understood in this way, connected with some content so as to create coherent wholes, form intentional actions. Therefore, they can be interpreted in accordance with the constructed model as sequences of applications of noetic functions to noematic functions whose values are intentional objects. From this standpoint, the mind 
can be modelled as a functional mechanism that generates a sequence of sequences of superposition of noetic functions with noematic functions representing intentional actions. This mechanism must, therefore, be understood as consisting of three types of modules of the function of synthesizing mental representations. The first module includes functional mechanisms for the synthesis of noetic representations, while the second one consists of functional mechanisms for the synthesis of noematic representations. The third module in turn integrates the first two, which results in mental reference acts directed toward intentional objects or situations.

From a theoretical point of view, one particular case of the model's functioning can be distinguished. It consists in the fact that the function of noetic synthesis is not active. Such noematic representations, which are not coordinated with any corresponding noetic representations, are responsible for the appearance of unintentional mental states in consciousness. They can be referred to as mental states with noetic gaps. Since the function of noetic synthesis $h$ is empty (and not active), its superposition $h(g)$ with the function of noematic synthesis $g$ must also be empty, so it cannot give an intentional object as its value, that is, generate an intentional act of reference. The sequences that make up the stream of consciousness are therefore not only composed of functions of type $h(g)$, but also of functions of type $g$ with noetic gaps. The functions of noematic synthesis with noetic gaps that are activated in the stream of consciousness in intentional actions are components of the mind that generate its unconscious states. In this case, the mind works, but unconsciously. This means that some functions of the noematic synthesis are activated in various structures of long-term memory understood as semantic mental representation stores. This may be formalized as follows.

$\begin{array}{ll}\text { (A7) } & (\forall h, g)\left[h \in N O E S I S \wedge \sim h^{*} \wedge g \in N O E M A \rightarrow g=h(g)\right] \\ \text { (A8) } & (\exists h, g)\left[h \epsilon N O E S I S \wedge \sim h^{*} \wedge g \in N O E M A \wedge g=h(g)\right]\end{array}$

On the basis of (DF1) and (A7), it is easy to prove the following theorems:

$$
\begin{aligned}
& (\forall g)\left[g \in R E F \wedge g \in N O E M A \rightarrow ( \exists h , g _ { i } ) \left(h \epsilon N O E S I S \wedge g_{i} \epsilon N O E M A \wedge g\right.\right. \\
& \left.\left.=h\left(g_{i}\right) \wedge g \neq g_{i} \wedge h^{*}\right)\right] \\
& (\forall g)\left[\sim g \epsilon R E F \wedge g \epsilon N O E M A \rightarrow ( \forall h , g _ { i } ) \left(h \epsilon N O E S I S \wedge g_{i} \epsilon N O E M A\right.\right. \\
& \left.\left.\wedge g=h\left(g_{i}\right) \rightarrow g=g_{i}\right)\right]
\end{aligned}
$$

According to (T1), if the function of noematic synthesis is also a reference function, then there is an active function of noetic synthesis that acts on some other function of noematic synthesis, producing a given function of noematic synthesis identical to a specific reference function. This means that if some reference function reduces itself to some function of noematic synthesis, then this reference function needs for its constitution some active function of noetic synthesis, which acts on some different function of noematic synthesis. Reference functions with noetic gaps, which take the shape: $g=h(g)$, are founded on reference functions without noetic gaps, which take the shape $g=h\left(g_{i}\right)$ where $g \neq g_{i}$. The theorem (T2) says that 
for each function of noematic synthesis which does not satisfy the role of reference functions, there is not a function of noetic synthesis that could synthesize a given function of noematic synthesis from other functions of noematic synthesis. According to the model of the noematic synthesis functions, presented in the second part of the work, this situation is not impossible. That is why, one may accept two additional hypotheses:

$$
\begin{aligned}
& (\mathrm{H} 1) \quad(\exists h, g)[g \in R E F \wedge g \in N O E M A \wedge h \epsilon N O E S I S \wedge g=h(g)] \\
& (\mathrm{H} 2) \quad(\exists h, g)[\sim g \epsilon R E F \wedge g \in N O E M A \wedge h \epsilon N O E S I S \wedge g=h(g)]
\end{aligned}
$$

It should be also noted that the case, when the function of noetic synthesis is active and the function of noematic synthesis is inactive, is theoretically impossible. It results from (A5) and (A6). Metaphorically speaking, an active noesis always looks for a noema, or in other words, when the mind is sleeping, it does not mean that it does not work.

Intentional actions as constituents of the stream of consciousness can be modelled as sequences of the shape: $\left\langle r_{1}, \ldots, r_{k}\right\rangle$, where $r_{1}, \ldots, r_{k}$ are mainly intentional reference functions and sometimes functions of noematic synthesis (in accordance with $\mathrm{H} 1$ and $\mathrm{H} 2$ ). Between these functions there are relationships that make these sequences integrated due to the connections between the functions of noetic synthesis and the functions of noematic synthesis. In this way, the stream of consciousness can be captured without the ego as a unifying factor (Zahavi 2005, 33-35).

\section{Noesis and Its Constituents}

Functions of noetic synthesis may be understood as formalizations of intentional experiences purified of all contents that appear in the stream of consciousness. They can be called the forces of consciousness which constitute the life of the mind. These noetic forces fill the awareness with contents formed in the noemata. Each function of noetic synthesis possess its own structure comprising other functions and moments as their arguments. The proposal to define functions of noetic synthesis (NOESIS) requires the construction of other theoretical structures, that is, functions of noetic intention, functions of noetic force, noetic modes, noetic moods and noetic qualia.

Let INTENTION be the set of all functions of noetic intentions, FORCE - the set of all functions of noetic force, and MODES — the set of all noetic modes.

(DF2) $(\forall h)\left[h \epsilon N O E S I S \equiv_{d f}(\exists i, f, m)(i \epsilon\right.$ INTENTION $\wedge f \epsilon F O R C E \wedge m \epsilon$ $M O D E S \wedge h=i(f, m)]$

According to (DF2), each function of noetic synthesis is a value of some function of noetic intention applied to an appropriate function of noetic force and some noetic mode. If noetic modes are also understood as functions, then each function of noetic synthesis is a superposition of some function of noetic intention with an 
appropriate functions of noetic force and some function of noetic modes. (DF2) shows that activation of the noetic synthesis function requires the activation of three additional functions, namely, some function of noetic intention, an appropriate function of noetic force and a corresponding function of noetic modes.

\subsection{Noetic Intentions}

Noetic intentions are the goals for which we perform our intentional acts of reference. For example, we can look at something with the intention of finding someone or something or with the intention of admiring or contemplating someone or something. Similarly, we can listen to overhear someone or to hear somebody. We may listen to the work of the car engine and listen to the noise of the cosmos. These two acts of hearing are governed by various noetic intentions. We can observe a situation with the intention of confirming it or overthrowing it. You can remember the same woman with the intention of identifying her or realizing her sensual beauty. A child may imagine Hell during a religion lesson to instill anxiety and fear in himself. By doing the same, an adult person can instill a sense of amusement in himself. Anxiety, fear and amusement may be the purposes for which we imagine various situations. We not only look, hear, perceive, smell, see, remember, imagine, assert, ask, say, tell, promise, etc. but we also conduct these acts for some purposes. Our intentional acts of reference are also mental expressions of our goals, that is, noetic intentions.

In the stream of consciousness, there are sometimes acts of intentional reference that are not accompanied by noetic intentions. Certainly, such acts are perceptions characterized by a high degree of receptivity. For example, when I suddenly hit my head with a pole, then my reference to such an object is receptive. The act of "sensory" perception of the pole, filled with sensory qualia of pain, in the situation of hitting the head in the pole, is not motivated by our noetic intention in general. Similarly, when we suddenly hear a thunder during a storm, our hearing of it is not caused by any noetic intentions. When we look at the room immediately after waking up from a nap, our intentional references in the acts of the visual perception of the ceiling, the hanging lamp or the open window are not motivated by any noetic intentions in such situations. When we wake up, we do not open our eyes for any purpose or intention. Noetic intentions begin to shape our perceptual acts only in the phases of the stream of consciousness following the moment of awakening (primarily for the purpose of making a decision to get out of bed). ${ }^{3}$

\footnotetext{
${ }^{3}$ The distinction between presentations characterized by receptivity (passivity) and activity was used in the Fichte's epistemology (1797/98). Kant's successor distinguished between presentations with a sense of necessity (receptive presentations) and with a sense of freedom. According to him, fantasies belong to the second category of presentations, while perceptual presentations belong to the first category. From this point of view, noetic intentions might be treated as volitional representations constituting functions of introducing noemata into intentional acts of reference. This proposal of comprehending of noetic intentions is consistent with the conception of Hintikka (1980), according to which the degree of intentionality of the mental act depends on its entanglement in the context of possible worlds. Noetic intentions might be interpreted as mental mechanisms of entangling intentional objects into an appropriate context of possible worlds.
} 
The conscious subject may not realize the noetic intentions in general. They often operate in a subconscious manner. The role of these intentions is to form the function of noetic synthesis by acting on the function of noetic force and some of its modes (in accordance with DF2).

\subsection{Noetic Forces}

A conscious subject can refer to the same intentional object or situation in an imaginative, perceptual or reminder way. One may remember a given situation, but one may also imagine it or finally observe it. What is more, the same situation can become the subject of our conjecture or even ascertainment. What distinguishes perceptions, acts of imagination, reminders, presumptions or establishing, is not the content that we assign to an intentional object or situation in a mental act. What differentiates these types of intentional reference are the states of the mind in which they are activated when the acts of intentional reference to an object or situation are conducted by it. The mind is in a different state when it visually perceives an apple hanging on a tree than when it imagines that the same apple is hanging on the same tree. Seeing, hearing, touching or judging the same object or situation are actions that are carried out on the basis of different mental states of the mind. Noetic forces are markers of mental states differentiating types of intentional acts of reference. In other words, noetic forces are peculiar functional properties of mental states underlying intentional acts of reference.

Mental states are filled with various types of qualia: hyletic data (sensory data), pain and pleasure data, emotive and volitional sensations (for instance: feeling of wellbeing and relaxation, sensations of various tensions and sense of suffering), data relying on a sense of understanding or misunderstanding something ${ }^{4}$ or finally data of visual, auditory or sensory awareness. ${ }^{5}$ Phenomenologists talk about the degree of saturation with qualia (especially with hyletic data) of acts of intentional reference to objects or situations. The kind of saturation of the mental state with qualia co-determines the fact that this saturation gives a particular type to acts of intentional reference. Saturation with auditory qualia of mental states is constitutive for acts of hearing something. Auditory qualia with visual qualia can also saturate acts of seeing something. Pain and pleasure data can saturate intentional acts of reference by the touch. It seems, however, that the type of saturation of mental states with

\footnotetext{
4 This type of qualia is present in the mental acts of hearing speech, which is articulated in a language unknown to us. Qualia of understanding appear in mental acts, in turn, when someone speaks to us in a language that is intelligible to us. Moreover, in typical perceptual situations, we also experience an understanding of what we perceive. From time to time, however, in our everyday life, we experience perceptual situations in which we experience some kind of a shock. For example, when we walk across the beach at dawn, we encounter a giant snot as big as a whale, which we are not able to identify. In this situation, we experience some sense of incomprehension.

${ }^{5}$ Husserl distinguishes two types of hyletic data. The first type comprises sensory data and the second type is consisted of the so called "sensorial sentiments". Hyletic data of the first type are non-egological and they participate in reference acts directed toward external space-time objects, whereas data of the second type are survived as "mine" and they participate in reference acts directed toward "my body" or "my corporeity" (Bello 2005, 2006).
} 
qualia is not the sole determinant of constituting in consciousness the type of an intentional reference act.

Intentional acts of reference are also accompanied by various moods of awareness of something that we often describe as "a sense or feeling of something"-for instance, a sense of reality, a sense of the presence of the recipient during speaking, the feeling that one is alive, the feeling that one is dying. They can be referred to as noetic moods. They have their content. In a certain way they are intentionally directed at something, to some content that can be described as the noematic background of an intentional reference act. Noetic moods are not moods in the psychological meaning, although the latter accompany the former as qualia saturating a given intentional act. Noetic moods, unlike moods in the psychological meaning, do not have an affective character. ${ }^{6}$

The fundamental noetic mood of almost every intentional act is the awareness of the surrounding world, a sense of reality or, in the end, the constant awareness that we are located in the so-called real world. This experience of reality (being in the real world), which accompanies almost every intentional act, is a fundamentally non-eliminable noetic mood from our stream of consciousness. ${ }^{7}$ The situation when the subject does not experience this "reality mood" of the world in which his intentional acts take place can be metaphorically compared to experiencing the mood of being in a "matrix". An equally fundamental mood is the awareness of my own self. The phenomenologists define this awareness as the moment of the egotic orientation of the intentional act. Another mood that cannot be eliminated from the stream of consciousness is the awareness of one's own life. Being aware of anything, each of us experiences a feeling of being alive and that some other things around us are also alive. In opposition to this vital awareness, a thanatic mood sometimes appears in the stream of consciousness as a feeling of dying. This noetic mood is revealed in expectation of one's death, especially in the elderly. Perhaps, people sentenced to death experience such a mood before execution. Both the sense of one's own life and the thanatic mood may mutually penetrate each other. The sense of the passage of time is also a noetic mood. However, this mood is not always present during the performance of intentional reference acts by the mind. In situations of solving a mathematical task with a high degree of abstraction, the mind sometimes loses some

\footnotetext{
6 Searle (1992, 127-151) thinks that moods are a constitutive element of any intentional state. According to him, the mood permeates all conscious forms of intentionality. Searle, however, deprives the mood from the status of intentional states. He understands moods in the psychological meaning. That is why, noetic moods cannot be understood as Searle's moods.

7 In Being and Time, Heidegger asserts that the constitutive property of the so-called Dasein (being which is intentionally directed towards being) is just being-in-the-world. Heidegger does not define Dasein as a mood in the psychological sense. Being-in-the-world is some permanent awareness of "being thrown into some reality," participating in any intentional action of consciousness that intentionally transcends reality. It seems that Heideggerian seiendes may be interpreted as noetic moods of various types. In Dreyfus (1991), the worldhood of Dasein is treated as the base of intentionality. This author asserts: 'Heidegger in Being and Time gives a description of the world in which man is at home. This world is organized from the start as a constellation of instruments referring to each other in terms of human purposes.' (Dreyfus 1971, 95). This may be understood that the worldhood of Dasein is shaped by human purposes as noetic intentions into intentional reference acts. (see Moran 2000).
} 
control over the passage of time. People experiencing such situations often talk about the feeling of "turning off". When we communicate with other people or with gods, then we experience inter-personal awareness, that is, a sense of community. Such a mood accompanies the acts of intentional reference, carried out in crowds: during political rallies, at sports stadiums or at meetings of politicians. The mood of sharing thoughts and feelings is accompanied by reference acts guided by collective intentions or we-intentions (see Tuomela and Miller 1988; Tuomela 2000). When religious people pray to the cross or a picture depicting a holy person, they do not experience that they are praying to a painted canvas or a piece of wood. In such situations, they experience a noetic mood of conversation with a personal being. ${ }^{8}$ After taking amphetamine, the mind often experiences some noetic mood of dominance, power, and advantage over the world. An opposite mood is the awareness of not being able to cope with the burden of the world, the sense of being overwhelmed by the world. People who want to commit to suicide may be experiencing such submissive noetic moods. In sacred acts of intentional reference, various numinous moods are revealed. The consciousness of being subjugated to some simultaneously frightening and fascinating force (power) is described in the literature on the phenomenology of religion (Otto, Eliade, van der Leeuew, and currently Bello). One may also speak of different hermeneutic moods that reveal themselves in interpretive actions. Then the mind experiences the possibilities of many interpretations of what it refers to. ${ }^{9}$ This mood can be described as Zoroastrian, referring to Nietzsche's philosophy of the superman.

A given mental act can be associated with many noetic moods during its implementation in the stream of consciousness. Thus, their various mergers are possible. Moreover, noetic moods have a variety of their intensity. For example, the presence of reality during the subject's performance of various physical activities is "as if stronger" than the same mood that makes itself present during our drowning in fairy-tale reading. These noetic moods and their mergers are constantly, dynamically activated or deactivated in the course of the stream of consciousness. Noetic moods are intentionally correlated with their content, which can be described as their noematic backgrounds. Intentional objects are therefore always given on a noematic background. Reality, irreality, unreality, surreality, possibility, fictitiousness, vitality, deadness, domination, submission, inter-personality, "communionshipness", temporality, and spatiality are examples of noematic backgrounds. Mergers of noetic moods evoke mergers of noematic backgrounds (Krysztofiak 2008, 266-268).

\footnotetext{
${ }^{8}$ In the philosophy of dialogue (Levinas, Buber, Rosenzweig), the noetic moods of conversation are the subject of phenomenological explorations. A particular mood of conversation manifests itself clearly in a situation of embarrassing oneself in front of another person.

9 This mood is described by Jaspers (1995) in his Philosophy of Existence as the "atmosphere of reason". According to him, this atmosphere spreads where the vigilant eye perceives reality itself, its possibilities and the infinitude of its interpretation. The atmosphere of reason is present in the most sublime literature. One may feel it in philosophy. Jaspers says that reason is 'mysticism for the intellect' and it develops all its possibilities to communicate with each other. This noetic mood could be understood as the experience of "pluralism of interpretation", as the awareness of the same from many points of view, in many interpretive sights. Using Hintikka's words, this mood might be described as a sense of traveling the mind across possible worlds along a multitude of world lines.
} 
In what way qualia bunches and fusions of noetic moods are transformed into noetic forces? What relationships take place between the bundles of qualia, mergers of noetic moods and noetic forces? Noetic intentions transform qualia and mergers of noetic moods into noetic forces of the intentional reference act.

For example, visual hyletic data (the type of qualia) and the mood of visual awareness consisting in the fact that one is aware of seeing something, blended with other moods, such as the sense of reality and the feeling of the present, are transformed thanks to the noetic intention of noticing something into noetic force of visual perception. We can visually perceive something if we have an intention to, for example, notice something, find something, meet someone, or finally do something. The noetic intention of solving some numerical task transforms the noetic numerical mood (the sense of contact with cardinalities or sizes) ${ }^{10}$ and qualia concerned with the sense of understanding the abstract content into the noetic force of the act of calculation. By acting on qualia and fusions of noetic moods, noetic intentions as functions create noetic forces. Let $Q U A L I A$ be the set of all qualia and MOOD be the set of all mergers of noetic moods, then the definition of noetic forces is as follows:

(DF3) $(\forall f)\left[f \in F O R C E \equiv_{d f}(\exists i, q, k)(i \epsilon I N T E N T I O N \wedge q \epsilon Q U A L I A \wedge k \epsilon\right.$

$$
M O O D \wedge f=i(q, k))]
$$

In light of (DF2) and (DF3), noetic intentions are functions that fulfill the role of integrating all other noetic elements into an act of intentional reference to a situation or some object. This construction of a noetic synthesis function is consistent with Heidegger's model of acts of intentionality as motivated by practical goals. Noetic intentions as functions may be understood as the mental sphere of praxis in the meaning of Heidegger: 'To rethink intentionality in terms of Dasein's transcendence, then, is to reintegrate intentionality into praxis' (Moran 2000, 59).

\subsection{Noetic Modes}

Noetic modes of intentional acts referring to an object or situation can be defined as the ways of implementing (realizing or performing) the noetic forces of these acts. For example, one can see something clearly or blurred, as if "behind a fog." The same applies to hearing acts. One may state a fact with a sense of certainty or doubt. The act of expressing liking someone can be realized euphorically or "phlegmatically". One can look at the beautiful woman in an impulsive fashion, and at a politician with disgust. One can praise someone in a humble or indulgent manner.

When we ask someone: how did he look at you? How did he abuse you? How do you love him?, then we may want to get the information about how their noetic force is realized in particular reference acts. Linguistic analyses of the

\footnotetext{
${ }^{10}$ In research on mental counting mechanisms, the researchers talk about a "number sense", that is, the attitude of organisms to detect cardinalities, ordinal numbers and sizes in the experienced world. Just as a man has the sense of sight, smell, touch or hearing, he(she) also has the number sense. This concept has been introduced to cognitive studies in Dehaene (1997).
} 
ways of using verbs in any language, resulting in the identification of various types of reference acts, can be an effective tool for reconstructing the ways of realizing the noetic forces of reference acts.

Each noetic force is correlated with the scope of its ways (modes) of implementation in intentional acts of reference. For example, the scope of the modes of the noetic force of the acts of looking at someone consists of, among others: expressiveness, vagueness, mindfulness, distraction, commitment, interest, boredom, indifference, unfriendliness, lust, greediness, contempt, etc. Therefore, one can look at one another in contemptuous or unfriendly manner. One can also look at someone carefully, greedily, and with interest. In acts of intentional reference to something with a certain noetic force, only some modes are implemented. Looking at someone with lust and commitment excludes looking at the same person with boredom. If I capture a certain logical pattern in a precise way, then I am unable to put it inattentively. If I am referring to the other person with a sense of pity, I am not able to refer to him or her with contempt at the same time. The noetic intention of the act of reference determines the modes with which its noetic force is realized. The noetic intention of the reference act selects appropriate modes from the scope of the noetic modes of the act. In other words, the aims for which we perform intentional acts of reference with given noetic forces determine the ways of their implementation (modes) in the act of intentional reference.

Noetic modes belong to the category of noetic characters, which are correlated by the laws of intentionality with the appropriate noematic characters called the ways of givenness of the objects of intentional reference acts (Føllesdal 1969; Smith and McIntyre 1982, 130-133).

By applying the definition of the noetic synthesis function (DF2) and the definition of the noetic force function (DF3) to (DF1), we obtain the following theorem:

$$
\begin{aligned}
& (\forall r)[r \in R E F \equiv(\exists i, q, k, m)(i \in I N T E N T I O N \wedge q \epsilon Q U A L I A \wedge k \epsilon M O O D \\
& \wedge \wedge m \epsilon M O D E S \wedge g \epsilon N O E M A \wedge r=i(i(q, k), m)(g) \wedge r \neq g)]
\end{aligned}
$$

According to (T3), every function of intentional reference $r$ is the superposition of some function of the noetic synthesis $i(i(q, k), m)$ with some function of the noematic synthesis $g$.

The function of noetic synthesis NOESIS is the structure that takes shape according to the statement (T3).

$$
\begin{aligned}
& (\forall h)\left[h \epsilon N O E S I S \equiv_{d f}(\exists i, q, k, m)(i \epsilon I N T E N T I O N \wedge q \epsilon Q U A L I A \wedge k \epsilon\right. \\
& M O O D \wedge m \epsilon M O D E S \wedge h=i(i(q, k), m))]
\end{aligned}
$$

The main component of the NOESIS function is the function of noetic intention, which operates on two levels. First the noetic intention acts on qualia and noetic moods, creating the function of a noetic force. Next, it creates a function of noetic synthesis, acting on the function of noetic force and its modes. 


\section{Subjectivity, Mind-Reading and Autism}

The sense of understanding another mind can be interpreted as the mood accompanying the actions of identifying intentional acts of reference of that mind. The ability to identify such actions is a component of mind-reading skills which are indispensable in our actions of reconstructing the subjectivity of others.

Mind-reading is understood as the ability to attribute mental states to the self and the other determined by folk theories of mind encoded in human heads (Premack and Woodruff 1978). This forms, in turn, the basis for further cognitive activities consisting in interpreting, predicting and explaining human behavior in terms of what takes place in our minds. It seems that our attributing mental states to the self and the other assumes the ability to identify intentional acts of reference performed by minds which we attribute their mental states to. According to the model of intentional act of reference presented above, the identification of reference acts includes two types of abilities, namely the ability to reconstruct the function of noetic synthesis and the ability to reconstruct the function of noematic synthesis. From this point of view mind-reading at the noetic level relies on the ability to identify $i(i(q, k), m))$ functions. This means that the ability to read the mind at the noetic level comprises four components: (1) the ability to identify noetic intentions, (2) the ability to identify noetic modes, (3) the ability to experience similar qualia, and (4) the ability to simulate similar noetic moods. The above-mentioned abilities may show different degrees of their effectiveness. Deep disorders in their functioning trigger the syndrome of autism at the noetic level. The etiology of autism at the noetic level can thus reach four different sources.

For example, if we are color blind, we are not able to experience visual qualia that other people experience when contemplating paintings. Therefore, it can be said that color-blind people have a difficult access to a kind of aesthetic experience. It is difficult for them to identify aesthetic acts of looking at paintings because of the lack of access to a specific type of qualia. In the same way, we are unable to comprehend the acts of reference of bats to various situations in their worlds. Therefore, we are not able to feel what it is like to be a bat (Nagel 1974). From a bat's point of view, we, as humans, are autistic. ${ }^{11}$ Some people are not able to simulate various noetic moods. For example, they do not have the access to anxiety. They are not able to be afraid, like the Vikings from the movie Asterix and Obelix: God Save Britannia. Our inability to simulate various moods (fears, euphoria, nostalgia, feelings of tragedy, feeling of being overwhelmed or finally feelings of domination over the world) when reading poetry is a sign of

\footnotetext{
11 Let us assume that most people in the world are color-blind. From their point of view, people who have access to color qualia are not able to look at the world in a black-and-gray way. One could say that such people are autistic in some peculiar way because they are unable to experience the world in the act of visual perception in the way that most people do in our imagined thought experiment. If the majority of people would experience the world sensually like bats, then the minority of humanity, which would function perceptually as we are currently perceiving the world in our perception acts, then from the majority point of view, the minority could be treated as a group of autistic subjects. In other words, if from my point of view, you are autistic, then from your point of view, I am autistic.
} 
impairment of the ability to experience various types of noetic moods. Some people do not have access to a sense of community. They do not understand then that one may, for example, participate in street demonstrations against political power. Disturbances or impairments in the ability to experience qualia and the ability to simulate noetic moods result, as defined in (DF3), disturbances or impairments in the ability to identify noetic forces. Many people have difficulty in recognizing how other people refer to things or situations. For example, they cannot recognize that someone is looking at them with hostility or boredom. On the first date, we often cannot see that our partner refers to us with fascination and interest, staring at us greedily. Sometimes we are blind to wooing. Such situations show that we have difficulty in identifying the noetic modes. Disturbances of this ability result in communication misunderstandings during interactions. The inability to identify other people's intentions is usually interpreted as the main source of autism. According to the presented model, the function of noetic intention generates a noetic synthesis function, which enables the mind to perform a reference act. Therefore, disturbances in the ability to identify various functions of noetic intention result in disturbances in the ability to identify the acts of reference of other minds. Ultimately, such disorders lead to the difficulty in attributing mental states to other minds. Thus, the presented model of the noetic synthesis function explains the fact of autism conceptualized in a standard way. It should be noted, however, that autism may appear not only as a disorder of the ability to identify noetic intentions, but as a disorder in the ability to simulate noetic moods or the ability to experience specific types of qualia, or finally as an impairment in the ability to identify noetic modes.

\section{Concluding Notes}

Intentionality understood as a stream of reference acts directed toward objects or situations inhabiting various worlds can be formalized as a series of applications of complex noetic-noematic functions of reference to neurophysiological states of the brain (nervous system). In the paper, the reference function model is formalized as a superposition of the noetic synthesis function with the function of noematic synthesis. The first function is also a complex structure built from other functions. The structure of the second function will be discussed in the second part of the work.

Issues regarding the ways of the implementation of various noetic synthesis functions in the mind are left open. In particular, the question of what syntactic form to represent noetic intentions, noetic forces, noetic modes, noetic moods and qualia, should be, however, resolved in the full formalization of the phenomenological conception of intentionality. Such a research task demonstrates its importance from the point of view of the construction of artificial intelligence simulating the human mind.

Acknowledgements The paper is part of the Project No. 2016/21/B/HS1/00821, supported by The National Science Centre, Poland. 
Open Access This article is distributed under the terms of the Creative Commons Attribution 4.0 International License (http://creativecommons.org/licenses/by/4.0/), which permits unrestricted use, distribution, and reproduction in any medium, provided you give appropriate credit to the original author(s) and the source, provide a link to the Creative Commons license, and indicate if changes were made.

\section{References}

Alves P (2013) Husserl's project for a material science of the life-world. In: New yearbook for phenomenology and phenomenological philosophy, vol 13, pp 118-152

Balza SQ (2009) Posibilidades logicas vs. posibilidades motivacionales: Un aporte husserliano a la teoria de la accion, Acta fenomenologica latinoamericana. Volumen III, Lima: Pontificia Universidad Catolica del Peru; Morelia (Mexico), Universidad Michoacana de san Nicolas de Hidalgo, pp 771-786

Banchetti M (1993) Føllesdal on the notion of noema: a critique. Husserl Stud 10:81-95

Barušs I (1989) Categorial modelling of Husserl's intentionality. Husserl Stud 6:25-41

Bello AA (2005) Phenomenological Hyletics and the lifeworld. In: Tymieniecka AT (ed) Analecta Husserliana, vol LXXXIV. Springer, Berlin, pp 293-301

Bello AA (2006) The language of our living body. In: Tymieniecka AT (ed) Acta Husserliana, vol LXXXIX. Springer, Berlin, pp 3-14

Dehaene S (1997) Number sense. Oxford University Press, New York

Dreyfus HL (1971) Phenomenology and mechanism. Noûs 5(1):81-96

Dreyfus HL (1991) Being in the world: a commentary on Heidegger's being and time, division I. MIT Press, Cambridge

Drummond JJ (1990) Husserlian intentionality and non-foundational realism. Noema and object. Kluwer Academic Publishers, Dordrecht

Drummond JJ (1997) Noema. In: Embree L, Behnke E, Carr D, Evans JC, Huertas-Jourda J, Kockelmans JJ, McKenna WR, Mickunas A, Mohanty JN, Seebohm TS, Zaner RM (eds) The encyclopedia of phenomenology. Springer, Dordrecht, pp 494-499

Fauconnier G (1994) Mental spaces: aspects of meaning. Construction in natural language. Cambridge University Press, Cambridge

Fauconnier G (2007) Mental spaces. In: Geeraerts D, Cuyckens H (eds) The Oxford handbook of cognitive linguistics. Oxford University Press, Oxford, pp 351-376

Fichte JG (1797/98) Versuch einer neuenDarstellung der Wissenschaftslehre. Erste Einleitung in die Wissenschaftslehre. Philosophisches Journal einer Gesselschaft Teutscher Geleheten (Polish translation by Garewicz J, Fichte JG (1986) Pierwsze wprowadzenie w teorię wiedzy. Półrocznik Filozoficzny Młodych. 1/1986, 194-224)

Føllesdal D (1969) Husserl's notion of noema. J Philos 66:680-687

Føllesdal D (1972) An introduction to phenomenology for analytic philosophers. In: Olson RE, Paul AM (eds) Contemporary philosophy in Scandinavia. John Hopkins University Press, Baltimore, pp 417-429

Gurwitsch A (1967a) Husserl's theory of the intentionality of consciousness in historical perspective. In: Lee EN, Mandelbaum M (eds) Phenomenology and existentialism. The John Hopkins Press, Baltimore, pp 25-57

Gurwitsch A (1967b) On the intentionality of consciousness. In: Kockelmans J (ed) Phenomenology. Doubleday, Garden City, pp 118-137

Heidegger M (1962) Being and time. Translated by Macquarrie J, Robinson E. Harper and Row, New York

Hintikka J (1975) The intentions of intentionality. In: The intentions of intentionality and other new models for modalities. Reidel Publishing Company, Dordrecht, pp 192-222

Hintikka J (1980) Degrees and dimensions of intentionality. In: Haller R, Grassl W (eds) Language, logic, and philosophy, proceedings of the fourth international Wittgenstein symposium 28 August to 2nd September 1979. Holder-Pichler-Tempsky, Vienna, pp. 283-296

Jaspers K (1995) Philosophy of existence. English translation by Grabau RF. University of Pennsylvania Press, Philadelphia 
Kosowski $Ł$ (2008) Noema in the light of contradiction, conflict and nonsense: noema as possibly thinkable content. Husserl Stud 24:243-259

Krysztofiak W (1995) Noemata and their formalization. Synthese 105(1):53-86

Krysztofiak W (2008) Baza empiryczna teorii referencji. In: Kochan E, Ziemski P (eds) Oblicza kultury. Człowiek-poznanie-twórczość. Profesor Halinie Perkowskiej w darze. Wydawnictwo Nakowe Uniwersytetu Szczecińskiego, Szczecin, pp 255-274

Marbach E (1993) Mental representation and consciousness. Towards a phenomenological theory of representation and reference. Kluwer Academic Publishers, Dordrecht

Marbach E (2010) Towards a formalism for expressing structures of consciousness. In: Gallagher S, Schmicking D (eds) Handbook of phenomenology and cognitive science. Springer, Dordrecht, pp $57-81$

Mohanty JN (1985) Intentionality and noema. In: The possibility of transcendental philosophy. Martinus Nijhoff Publishers, Dordrecht, pp 13-24

Moran D (2000) Heidegger's critique of Husserl's and Brentano's accounts of intentionality. Inquiry 43:39-66

Nagel T (1974) What is it like to be a bat. Philos Rev 83:435-450

Premack D, Woodruff G (1978) Does the chimpanzee have a theory of mind? Behav Brain Sci 4:515-526 Searle JR (1992) The rediscovery of the mind. MIT Press, Cambridge

Smith DW, McIntyre R (1982) Husserl and intentionality: a study of mind, meaning, and language. D. Reidel, Dordrecht

Sokolowski R (1987) Husserl and Frege. J Philos 84(10):521-528

Tuomela R (2000) Collective and joint intention. Mind Soc 1(2):39-69

Tuomela R, Miller K (1988) We-intentions. Philos Stud 53:115-137

Yoshimi J (2007) Mathematizing phenomenology. Phenomenol Cogn Sci 6:271-291

Yoshimi J (2016) Husserlian Phenomenology. A Unifying Interpretation. Springer, Merced

Zahavi D (2004) Husserl's noema and the internalism-externalism debate. Inquiry 47(1):42-66

Zahavi D (2005) Subjectivity and selfhood. Investigating the first-person perspective. The MIT Press, London

Publisher's Note Springer Nature remains neutral with regard to jurisdictional claims in published maps and institutional affiliations. 